https://doi.org/10.1590/198053146432

\title{
PERFIS DE ESTAGIÁRIOS NA PRÁTICA DE ENSINO SUPERVISIONADA EM PORTUGAL
}

\author{
Catarina Tomás' \\ Carolina Gonçalves"
}

\section{Resumo}

Este artigo apresenta a identificação de três perfis exploratórios de padrões de práticas reflexivas de 115 estudantes-estagiários/as que frequentam os mestrados de formação de educadores/as de infância e professores/as do $1^{\circ}$ e do $2^{\circ}$ ciclo do ensino básico, em Portugal continental, em relação à prática de ensino supervisionada (PES). Os dados apresentados, resultantes da análise estatística baseada na análise de correspondências múltiplas (ACM), permitem identificar dois perfis diferenciados pelo impacto das reflexões escritas durante a PES e respetiva justificação, pelo subsistema de ensino superior que frequentam, pela natureza jurídica do subsistema e pelos modelos adotados, bem como um terceiro grupo diferenciado pelo modelo pedagógico adotado e pelo subsistema frequentado.

PRÁTICA DE ENSINO • SUPERVISÃO • EDUCAÇÃO BÁSICA • ENSINO SUPERIOR

\section{PROFILES OF TRAINEES IN SUPERVISED TEACHING PRACTICE IN PORTUGAL}

\section{Abstract}

This article presents three exploratory profiles of reflexive practices from a sample of 115 student-trainees who attend teacher training masters programs in early childhood education and in teaching 1st and 2nd cycle of basic education, in mainland Portugal, regarding prática de ensino supervisionada (PES) [supervised teaching practice]. The data presented comes from the statistical analysis based on análise de correspondências múltiplas (ACM) [multiple correspondence analysis]. It allows to identify two profiles set apart by the impact of the reflections written during STP and their respective justification based on the subsystem of higher education they attend, the legal nature of the subsystem and the adopted models. The data also differentiated a third group based on the pedagogical model adopted and the subsystem.

\section{PRACTICE TEACHING • SUPERVISION・BASIC EDUCATION • HIGHER EDUCATION}

I Instituto Politécnico de Lisboa, Escola Superior de Educação e Centro Interdisciplinar de Ciências Sociais (CICS/NOVA) da Universidade NOVA de Lisboa (FCSH/NOVA), Lisboa, Portugal; http://orcid.org/0000-0002-9220-964X: ctomas@eselx.ipl.pt

II Instituto Politécnico de Lisboa, Escola Superior de Educação e Centro Interdisciplinar de Ciências Sociais (CICS/NOVA) da Universidade NOVA de Lisboa (FCSH/NOVA), Lisboa, Portugal; http://orcid.org/0000-0002-3176-2601; carolinag@eselx.ipl.pt 


\section{PROFILS DES STAGIAIRES DANS LE CADRE DE LA PRATIQUE SUPERVISÉE DE L'ENSEIGNEMENT AU PORTUGAL}

\section{Résumé}

Cet article identifie trois profils exploratoires de modèles de pratiques réflexives concernant la pratique supervisée de l'enseignement (PSE), de 115 étudiants enrôlés en maitrises de formation pour éducateurs/trices de l'enfance et des enseignants des 1er et 2nd cycles de l'éducation de base, au Portugal. Les données proviennent de l'analyse statistique, appuyée sur l'analyse des correspondances multiples (ACM). Ces données permettent d'identifier deux profils qui se différencient non seulement par l'impact des réflexions rédigées pendant la PSE et leur respectives justifications, mais aussi par le sous-système de l'enseignement supérieur choisi par les stagiaires, par la nature juridique du sous-système ainsi que par les modèles adoptés. Un troisième groupe a aussi pu être différencié par le modèle pédagogique adopté et par le sous-système d'enseignement.

\section{PRATIQUE D'ENSEIGNEMENT • SURVEILLANCE • ÉDUCATION DE BASE • ENSEIGNEMENT SUPÉRIEUR}

\section{PERFILES DE ESTUDIANTES EN PRÁCTICAS EN LA ENSEÑANZA SUPERVISADA EN PORTUGAL}

\section{Resumen}

Este artículo presenta la identificación de tres perfiles exploratorios de patrones de prácticas reflexivas de 115 estudiantes en prácticas que participan en la maestría en formación de docentes de educación infantil y profesores /as de primer y segundo ciclo de enseñanza básica en Portugal continental, en relación con la prática de ensino supervisionada [práctica de enseñanza supervisada] (PES). Los datos presentados, resultantes del análisis estadístico basado en el análisis de correspondencias múltiples (ACM), permiten identificar dos perfiles diferenciados por el impacto de las reflexiones escritas durante la PES y su respectiva justificación, por el subsistema de educación superior al que asisten, por la naturaleza jurídica del subsistema y por modelos adoptados, así como un tercer grupo diferenciado por el modelo pedagógico adoptado y por el subsistema al que asistieron.

\section{PRÁCTICA DE ENSEÑANZA • SUPERVISIÓN • EDUCACIÓN BÁSICA • ENSEÑANZA SUPERIOR}


REFLEXÃO SOBRE A PRÁTICA DE ENSINO SUPERVISIONADA (PES),' PODENDO SER entendida como locus de reprodução, questionamento, experimentação, ação, vivências e aprendizagens, de múltiplas inter-relações socioculturais, políticas e organizacionalmente contextualizadas, continua a marcar a discussão sobre formação de educadores/as e professores/as.

Efetivamente, não se trata de um tema novo nas ciências da educação. Todavia, as intensas e aceleradas transições paradigmáticas na formação de profissionais que trabalham com crianças até aos 12 anos, em Portugal, enunciam questões e análises com novas nuances. Assistimos, desde 1992, a um conjunto de alterações no já longo e complexo processo de formação de educadores/as e professores/as, via adesão ao Processo de Bolonha, caracterizado por diversos autores como política educacional supranacional, tendo em vista "um movimento em direção à convergência” (LIMA; AZEVEDO; CATANI, 2008, p. 14) institucional, organizacional e ideológica, que marca um processo de redefinição de funções, identidades e trajetórias dos/as profissionais de educação (SERRALHEIRO, 2005; FERREIRA; FERNANDES, 2015; TOMÁS; GONÇALVES, 2018; EUROPEAN COMMISSION/EACEA/EURYDICE, 2018). 
Em Portugal, o início do novo século trouxe mudanças profundas no que diz respeito ao processo de formação daqueles/as profissionais. As mudanças mais presentes remetem-nos para um conjunto de desassossegos reais, tanto dos/as docentes do ensino superior e dos/as educadores/as e/ou professores/as cooperantes, como dos/as estudantes em relação à formação, em geral, e à PES, em particular. Destacam-se, entre outras dimensões: a crescente academização da formação; a pouca autonomia das instituições de ensino superior na organização dos planos de estudos; a ausência de participação dos/as professores/as e dos/as estudantes do ensino superior na discussão desses planos; a sobrevalorização de determinadas áreas de conhecimento, como a matemática e o português, sobretudo entre 2011 e 2015; os discursos sobre a prática docente em permanente tensão, ou mesmo em contradição, com a ação pedagógica; assim como o insuficiente número de horas PES na formação de educadores/as e professores/as, tanto na licenciatura como no mestrado ${ }^{2}$ (ESTRELA; ESTEVES; RODRIGUES, 2002; LEITE, 2005; SERRALHEIRO, 2005; CARDONA, 2008; ALARCÃO; ROLDÃO, 2010; BIANCHETTI; SGUISSARDI, 2009; RAMALHO, 2015; COCHRAN-SMITH; VILLEGAS, 2016; FERREIRA, 2016; GALVÃO; PONTE, 2018; TOMÁS; GONÇALVES, 2018).

O debate em torno das questões associadas à formação de educadores/as e professores/as, nomeadamente sobre a PES, deve ser equacionado no quadro de um envolvimento mais diversificado de atores sociais. A discussão continua a assumir a centralidade na academia portuguesa, no entanto, pouco tem sido o envolvimento dos legisladores, educadores/as e professores/as cooperantes, políticos/as ou estudantes. No fundo, estamos perante uma ausência de discussão robusta e promotora de diálogo entre saberes ou um pensamento abissal ${ }^{3}$ (SANTOS, 2007), neste caso interno. Tentando contrariar a afonia de alguns atores identificados, neste artigo centramos a análise, no âmbito de uma pesquisa mais ampla (TOMÁS; GONÇALVES, 2018), nas representações de 115 estudantes que frequentam os mestrados de formação de educadores/as de infância e professores/as do $1^{\circ}$ e do $2^{\circ}$ ciclo do ensino básico, em Portugal continental. O estudo teve como objetivos desvendar o posicionamento dos/as estudantes em relação à PES e identificar perfis exploratórios de práticas dos/as estudantes-estagiários/as sobre a PES (reflexões escritas, subsistema de ensino superior e modelos pedagógicos).

2 Atualmente, os cursos de formação de educadores/as e professores/as do $1^{\circ}$ e $2^{\circ} \mathrm{CEB}$ organizam-se num ciclo bietápico constituído por uma licenciatura em educação básica (seis semestres), que não habilita para a docência, e um mestrado profissionalizante (dois a quatro semestres, consoante o nível ou níveis para os quais se está a formar), que habilita para o exercício da profissão. No que diz respeito à PES, a legislação denomina Iniciação à Prática Profissional, para referenciar a componente de formação da prática pedagógica ( $1^{\circ}$ ciclo de estudos) e Prática de Ensino Supervisionada, para o estágio de natureza profissionalizante ( $2^{\circ}$ ciclo de estudos). Consultar o Decreto-lei n. 43/2007, de 22 de fevereiro (PORTUGAL, 2007), e o Decreto-Lei n. 79/2014, de 14 de maio (PORTUGAL, 2014).

3 Para Boaventura de Sousa Santos (2007, p. 71), o pensamento abissal: "consiste num sistema de distinções visíveis e invisíveis, sendo que estas últimas fundamentam as primeiras. As distinções invisíveis são estabelecidas por meio de linhas radicais que dividem a realidade social em dois universos distintos: o 'deste lado da linha' e o 'do outro lado da linha' A divisão é tal que 'o outro lado da linha' desaparece como realidade, torna-se inexistente e é mesmo produzido como inexistente. [...]. A característica fundamental do pensamento abissal é a impossibilidade da co-presença dos dois lados da linha. O universo 'deste lado da linha' só prevalece na medida em que esgota o campo da realidade relevante: para além da linha há apenas inexistência, invisibilidade e ausência não-dialética". 


\section{ENQUADRAMENTO METODOLÓGICO}

A pesquisa desenvolvida assume uma abordagem de multimétodo, ainda que, neste artigo, se apresente um recorte da mesma, em que a análise tem uma natureza quantitativa. A partir de um processo multietápico:

- construiu-se um inquérito, para a recolha dos dados, aplicado aos/às estudantes dos cursos acima referidos, entre março e abril de 2018, validado antes da sua aplicação;

- identificaram-se os 66 cursos de mestrado profissionalizante de formação de educadores/as e de professores/as de $1^{\circ}$ e $2^{\circ} \mathrm{CEB}$, em funcionamento no ano letivo de 2017/2018, a partir da página da Agência de Avaliação e Acreditação do Ensino Superior (A3ES); ${ }^{4}$

- contactaram-se os/as coordenadores/as ou diretores/as de curso para solicitar a divulgação do inquérito junto dos/as estudantes.

Responderam voluntariamente ao inquérito 115 estudantes. A recolha de dados pautou-se por um conjunto de dificuldades que podem explicar o tamanho da amostra: a ausência de listas de e-mail de estudantes; a não resposta aos e-mails enviados às/aos coordenadores/as de curso; e a dificuldade em encontrar nas páginas de algumas instituições de ensino superior a pessoa de referência do curso (coordenador/a). Assim, orientadas por princípios de experimentação e de superação de limites, consideramos que esta pesquisa assume uma natureza indagatória e exploratória. Para a análise dos dados, recorreu-se a uma análise estatística, utilizando o SPSS Statistics ${ }^{\circledast}$ (IBM SPSS, versão 24.0, Chicago, EUA) e o nível de significância foi estabelecido em $p<0,05$.

Numa primeira fase, foi caracterizada a amostra em estudo e feita uma análise descritiva dos dados em função da natureza das variáveis estudadas. Foram realizadas estatísticas descritivas, incluindo média, desvio padrão, frequências e percentagens para a totalidade da amostra e por curso de mestrado. Na segunda fase, de forma a segmentar os/as inquiridos/as, os dados apresentados resultam da análise estatística baseada na análise de correspondências múltiplas (ACM) (CARVALHO, 2008), o que possibilitou a construção de dimensões/índices (configuração topológica) de carácter exploratório.

\section{PARTICIPANTES}

Os/as 115 participantes neste estudo frequentaram, em 2017/2018, um curso de mestrado de formação de educadores/as de infância (MEPE), de educadores/as e professores/as de $1^{\circ} \mathrm{CEB}$ (PE $1^{\circ} \mathrm{CEB}$ ) ou de professores/as de $1^{\circ}$ e de $2^{\circ} \mathrm{CEB}$ (PE $2^{\circ}$ CEB) em Portugal continental (17,4\% do norte, $16,5 \%$ do centro, $54,8 \%$ de Lisboa, $5,2 \%$ do Alentejo e 6,1\% do Algarve).

4 A A3ES, criada em 2010, é responsável por analisar o cumprimento do que é legalmente definido para a formação de educadores/as e professores/as e avaliar a sua qualidade. 
Destes/as, 111 (96,5\%) são mulheres e quatro são homens (3,5\%) com idades entre 21 e 54 anos e uma média de $24,39( \pm 4,5)$ anos.

No que diz respeito ao tempo de duração de cada PES já realizada, 20,9\% dos/as estudantes indicaram entre 1 e 2 meses, 55,7\% mencionaram 3 meses ou mais e 23,5\% não responderam à questão.

É importante referir que a organização da PES varia em função das opções das instituições de ensino superior, o que quer dizer que há quem tenha estado nos contextos de PES cinco dias seguidos, outros/as três dias por semana, outros/as três manhãs por semana, entre outras modalidades.

A maior parte dos/as estudantes frequentava instituições públicas, seja universidade ou instituto politécnico (Tabela 1). Do curso de Mestrado em Educação Pré-Escolar (MEPE), 70,6\% estavam na universidade pública e $84,2 \%$ no politécnico público. Cerca de $45 \%$ encontravam-se em instituições privadas, dos quais $29,4 \%$ na universidade e $15,8 \%$ no politécnico. O curso de PE $1^{\circ} \mathrm{CEB}$ era frequentado por $54,5 \%$ na universidade pública e $45,5 \%$ na privada; $93,3 \%$ dos estudantes no politécnico estavam numa instituição pública. Não se verificou a frequência de estudantes dos cursos de $2^{\circ}$ CEB em universidade, seja pública ou privada. Neste caso, são cursos que habilitam para a docência em $1^{\circ} \mathrm{CEB}$ e em Mestrado em Ensino do $1^{\circ}$ Ciclo do Ensino Básico e de Português e História e Geografia de Portugal no $2^{\circ}$ Ciclo do Ensino Básico (MPHGP) e Mestrado em Ensino do $1^{\circ}$ Ciclo do Ensino Básico e de Matemática e Ciências Naturais no $2^{\circ}$ Ciclo do Ensino Básico (MMCN). Dos/as alunos/as dos cursos de $2^{\circ} \mathrm{CEB}$, todos frequentavam o politécnico, sendo 94,1\% numa instituição pública e 5,9\% numa instituição privada.

TABELA 1

DISTRIBUIÇÃO DOS/AS ESTUDANTES, NO ANO LETIVO 2017-2018, SEGUNDO O CURSO, A NATUREZA JURÍDICA E O SUBSISTEMA

\begin{tabular}{|c|c|c|c|c|c|}
\hline \multirow{2}{*}{ CURSO } & \multirow{2}{*}{$\begin{array}{l}\text { TOTAL } \\
\text { N (\%) }\end{array}$} & \multirow{2}{*}{$\begin{array}{l}\text { NATUREZA } \\
\text { JURÍDICA }\end{array}$} & & \multicolumn{2}{|c|}{ SUBSISTEMA } \\
\hline & & & & UNIVERSIDADE & POLITÉCNICO \\
\hline \multirow[t]{3}{*}{ MEPE } & $55(47,8)$ & & & & \\
\hline & & pública & $44(45,8)$ & $12(70,6)$ & $32(84,2)$ \\
\hline & & privada & $11(57,9)$ & $5(29,4)$ & $6(15,8)$ \\
\hline \multirow[t]{3}{*}{$\mathrm{PE} 1^{\circ} \mathrm{CEB}$} & $26(22,6)$ & & & & \\
\hline & & pública & $20(20,8)$ & $6(54,5)$ & $14(93,3)$ \\
\hline & & privada & $6(31,6)$ & $5(45,5)$ & $1(6,7)$ \\
\hline \multirow[t]{3}{*}{$2^{\circ} \mathrm{CEB}$} & $34(29,6)$ & & & & \\
\hline & & pública & $32(33,3)$ & $O(0,0)$ & $32(94,1)$ \\
\hline & & privada & $2(10,5)$ & $O(0,0)$ & $2(5,9)$ \\
\hline
\end{tabular}

Fonte: Elaboração das autoras, com base nos dados do questionário.

\section{APRESENTAÇÃO E DISCUSSÃO DOS DADOS}

Com o objetivo de identificar padrões de prática dos/as estudantes-estagiários/as relativamente às reflexões escritas sobre a PES, recorreu-se a uma ACM. O cruzamento das variáveis, apresentadas em coluna, através deste procedimento 
estatístico, permitiu a identificação de duas dimensões responsáveis por 68,5\% da inércia total (valor próprio da primeira dimensão=0,382; valor próprio para a segunda dimensão=0,303), conforme se pode verificar na Tabela 2. Ambas apresentam níveis adequados de consistência e bons valores de inércia.

TABELA 2

DISCRIMINAÇÃO E CONTRIBUIÇÃO DAS VARIÁVEIS NAS DIMENSÕES

\begin{tabular}{l|c|c|c|c}
\hline \multirow{2}{*}{} & \multicolumn{2}{|c|}{$\begin{array}{c}\text { DIMENSÃO 1 } \\
\text { (REFLEXÕES SOBRE A PES) }\end{array}$} & $\begin{array}{c}\text { DIMENSÃO 2 } \\
\text { (SUBSISTEMA E MODELOS) }\end{array}$ \\
\cline { 2 - 5 } & DISCRIMINAÇÃO & CONTRIBUIÇÃO & DISCRIMINAÇÃO & CONTRIBUIÇÃO \\
\hline Pública ou privada & 0,006 & $0,24 \%$ & $\mathbf{0 , 3 1 3}$ & $17,2 \%$ \\
\hline Universidade ou politécnico & 0,003 & $0,14 \%$ & $\mathbf{0 , 4 5 6}$ & $25,0 \%$ \\
\hline Modelos pedagógicos & 0,294 & $12,8 \%$ & 0,331 & $18,2 \%$ \\
\hline Impacto das reflexões & $\mathbf{0 , 8 5 9}$ & $37,4 \%$ & 0,027 & $1,5 \%$ \\
\hline Justificação do impacto das reflexões & $\mathbf{0 , 9 0 9}$ & $39,6 \%$ & $\mathbf{0 , 4 2 3}$ & $23,3 \%$ \\
\hline Áreas científicas da PES & $\mathbf{0 , 2 2 4}$ & $9,8 \%$ & 0,270 & $14,8 \%$ \\
\hline Total & 2,295 & 100,0 & 1,820 & 100,0 \\
\hline Inércia & $\mathbf{0 , 3 8 2}$ & & 0,303 & \\
\hline \% de variância explicada & 55,7 & 44,3 & \\
\hline
\end{tabular}

Fonte: Elaboração das autoras, com base nos dados do questionário.

As variáveis impacto das reflexões (ter ou não ter impacto) e justificação do impacto das reflexões discriminam mais na dimensão 1, pelo que se optou pela designação de reflexões sobre a PES. Por sua vez, as variáveis pública ou privada (frequência de um curso numa instituição de ensino superior de natureza pública ou privada), universidade ou politécnico e modelos pedagógicos têm maior destaque na dimensão 2. Nesse sentido, considerou-se ser a dimensão que descreve subsistema e modelos.

A apresentação dos resultados é feita em duas partes: síntese do posicionamento dos/as estudantes em relação à PES; e identificação das práticas dos/as estudantes sobre PES no que diz respeito às reflexões escritas, ao subsistema de ensino superior que frequentam e aos modelos pedagógicos que privilegiam durante a PES.

\section{POSICIONAMENTOS EM RELAÇÃO À PES}

Nesta secção, apresentam-se, de forma sintética, os posicionamentos dos/as estudantes-estagiários/as relativamente à importância da PES, aos modelos pedagógicos que privilegiam durante a PES, às áreas científicas que consideram mais relevantes durante a PES, assim como aos/às autores/as que mais convocam, à fundamentação teórica e à periodicidade das reflexões escritas sobre a PES.

Relativamente à importância da PES, 33,0\% dos/as estudantes referiram que se trata de uma aprendizagem em contexto, atribuindo valor ao papel do/a orientador/a cooperante, e, para 30,4\%, é o lugar para pôr em prática a teoria. A PES também é vista como um processo de crescimento pessoal e/ou profissional $(28,7 \%)$. 
Para 7,8\% dos/as estudantes, as respostas inserem-se na categoria outras respostas, maioritariamente críticas.

Os modelos pedagógicos mais privilegiados na PES $\left(\chi^{2} \quad(24)=43,167\right.$, $\mathrm{p}=0,010)$ são: o Movimento da Escola Moderna (MEM) (27,0\%); a Pedagogia de Projeto (10,4\%); “um pouco de cada” (9,6\%); o HighScope (9,6\%); o MEM e HighScope (9,6\%); um modelo em função do contexto (6,1\%); e outros (16,5\%). Para além desses modelos identificados, 7,0\% dos/as estudantes mencionaram não recorrer a modelos e 4,3\% não souberam identificar um modelo ou não responderam à questão colocada.

Neste campo, importa destacar não só os modelos privilegiados pelos/as estudantes, que se adequam aos públicos com quem interagem na PES, mas também a elevada percentagem de referência a outros modelos, ora incorretamente identificados, ora inexistentes.

Relativamente às componentes de formação, 63,5\% dos/as estudantes reconheceram que a área científica Educacional Geral é aquela que mais suporta a PES, seguida do duo Educacional Geral e Didáticas Específicas (10,4\%), especificamente referentes às áreas dos mestrados. Destacam-se como áreas científicas o par Psicologia e Pedagogia (48,7\%), a Pedagogia (26,3\%) e a Psicologia $(14,5 \%)$. Com valores pouco relevantes, o trio Psicologia-Pedagogia-Sociologia (6,6\%), o par Pedagogia-Sociologia $(1,3 \%)$ e Sociologia $(1,3 \%)$.

Em relação à reflexividade e à teorização da prática pedagógica, tão necessária quão difícil de se fazer, da opinião dos/as estudantes, quando questionados acerca dos autores/as que mais convocaram para a PES, sobretudo nas reflexões teóricas, parece sobressaírem duas premissas: a valorização de autores clássicos da Psicologia, como Lev Vygotsky e Jean Piaget; e a existência de alguma especificidade em relação ao curso de maior expressão em autores/as nacionais.

A maioria dos/as estudantes $(74,8 \%)$ afirmou que convocam fundamentação teórica quando da realização das reflexões escritas, $12,2 \%$ indicaram não o fazer e 13,0\% não responderam à questão. Daqueles que o fazem, 89,6\% consideram que as reflexões têm impacto na prática pedagógica. Apenas 10,4\% afirmaram o contrário.

No que diz respeito à periocidade das reflexões $\left(\chi^{2}(8)=8,085, p=0,425\right)$, 41,7\% mencionaram realizá-las semanalmente, $20,9 \%$ fazem diária e semanalmente, $14,8 \%$ quinzenal/mensalmente e $7,0 \%$ indicaram diariamente. Dentro desta periodicidade, verifica-se que, de um modo geral, quem faz reflexões no âmbito da PES recorre à fundamentação teórica. No entanto, aqueles/as que as realizam semanalmente são os que mais recorrem à fundamentação teórica $(29,6 \%)$, em oposição a quem realiza reflexões numa base diária (5,2\%). São também os/as estudantes que realizam reflexões semanalmente que não recorrem à fundamentação teórica $(7,8 \%)$ ou que não responderam a esta questão $(4,3 \%)$.

A maioria dos/as estudantes $(71,8 \%)$ afirmou que as reflexões se configuram como um mecanismo de regulação/avaliação da ação. Para 23,3\%, as reflexões assumem-se como um processo de introspeção. 
Em síntese, há um reconhecimento da importância da mobilização teórica no momento das reflexões escritas, parecendo possível inferir-se que existe uma consciência de que os marcos teóricos ajudam na construção da profissão e no desenvolvimento profissional do/a futuro/a educador/a ou professor/a.

\section{PERFIS EXPLORATÓRIOS DOS/AS ESTUDANTES-ESTAGIÁRIOS/AS}

A análise das duas dimensões permitiu verificar os principais eixos estruturantes deste espaço topográfico, bem como identificar três perfis exploratórios de estudantes-estagiários/as (Figura 1).

Uma primeira dimensão, orientada segundo o eixo horizontal, estabelece uma diferenciação do impacto das reflexões escritas na PES (ter ou não ter) e a justificação para esse impacto e uma segunda dimensão, correspondente ao eixo vertical, é estruturada segundo diferenciados perfis de subsistema de ensino superior que os/as estudantes frequentam e os modelos pedagógicos adotados na PES.

\section{FIGURA 1}

\section{PERFIS EXPLORATÓRIOS DE PRÁTICAS REFLEXIVAS DOS/AS ESTUDANTES NA PES}

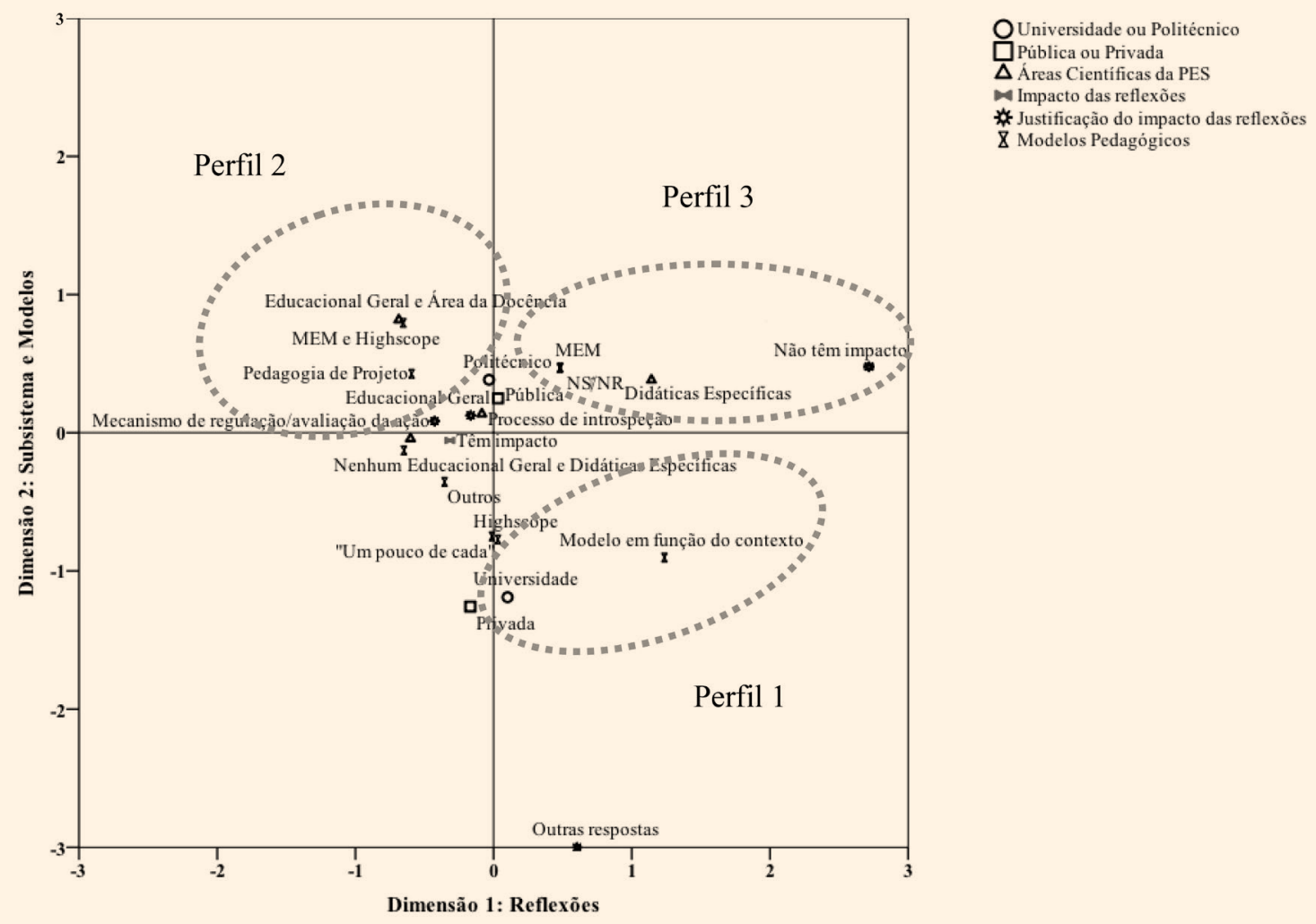

Fonte: Elaboração das autoras, com base nos dados do questionário.

Uma observação preliminar permite realçar que é no quadrante superior esquerdo (quadrante 2) que as reflexões escritas têm impacto na PES e que se localizam as categorias reveladoras de maior informação relativamente às variáveis em análise. 
Identifica-se, assim, no quadrante inferior direito, um primeiro perfil (quadrante 4), que informa de maneira sintética a associação entre a adoção do modelo pedagógico em função do contexto e a proximidade da categoria relativa ao ensino universitário.

No quadrante superior esquerdo, observa-se outra configuração que associa um segundo perfil integrado por estudantes que afirmaram que as reflexões escritas têm impacto na PES e se configuram como um mecanismo de regulação/ avaliação da ação ou como um processo de introspeção. Os/as estudantes parecem privilegiar as componentes de formação de Educacional Geral-Área da Docência e de Educacional Geral e, quanto aos modelos pedagógicos, destacam-se o MEM e o HighScope. Regista-se ainda, neste perfil, a frequência do politécnico público.

O perfil 3, por oposição ao anterior, é marcado pelo facto de as reflexões não terem impacto na PES e por privilegiar as Didáticas Específicas. É ainda possível destacar uma associação entre as referidas Didáticas Específicas, o modelo pedagógico do MEM e estudantes que não sabem ou não responderam à questão.

A Figura 2 permite confirmar que a variável curso (variável suplementar) é diferenciadora na definição dos perfis. As categorias estão dispostas de forma diferenciada pelos vários quadrantes. São os/as estudantes do MEPE e do $2^{\circ} \mathrm{CEB}$ que se concentram mais no perfil 2 , ou seja, são aqueles que reconhecem que as reflexões escritas sobre a PES têm impacto na sua prática. Esse perfil 2 é constituído por estudantes que frequentam o politécnico público e privilegiam o MEM e o HighScope como modelos pedagógicos.

\section{FIGURA 2}

\section{DISPOSIÇÃO DOS/AS ESTUDANTES SEGUNDO O CURSO}

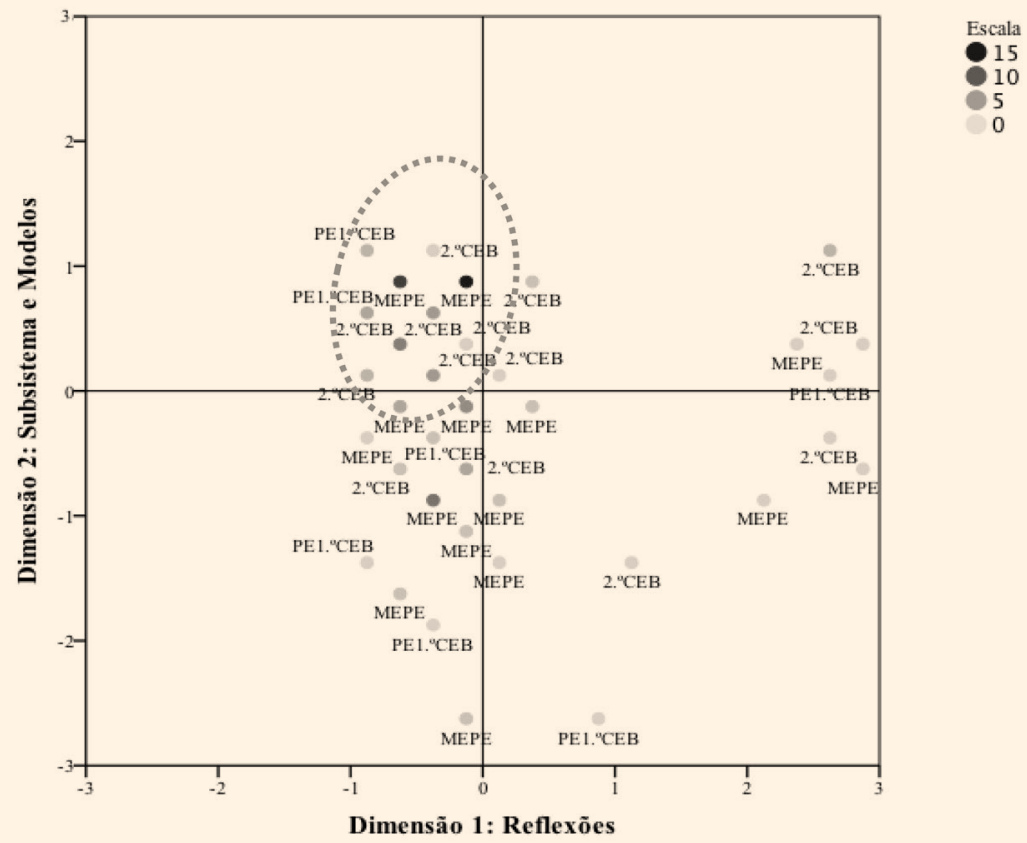

Fonte: Elaboração das autoras, com base nos dados do questionário. 


\section{CONSIDERAÇÕES FINAIS OU UMA LENTIDÃO QUE SE EXIGE NA PES}

Não deixando de assinalar a importância simbólica e substantiva que a PES ocupa nos cursos de formação de educadores/as e/ou professores/as, ouvir os/as estudantes possibilitou mapear um conjunto de significações e valores que poderão potenciar uma discussão mais ampla e uma avaliação sobre a formação destes/as futuros/as profissionais pós-Bolonha. Trata-se de uma tentativa de "pôr ordem na complexidade da realidade" (DEMAZIÈRE, 2013, p. 333).

A formação de educadores/as e professores/as parece, no atual modelo, ter sido estruturada em torno de um modelo aditivo, em que se privilegia a temporalidade mais ou menos curta em relação à PES, que, para além de intensificar os ritmos de trabalho, da "performance pedagógica" dos/as estudantes e dos/as docentes de ensino superior, impõe uma espécie de inversão epistemológica e educativa, pouco congruente com os processos e as dimensões que a investigação neste campo defende, ou seja, um outro tempo e outras relações com o saber.

Os resultados parecem revelar realidades que não deixam de ser surpreendentes, ainda que captadas de forma aparentemente passageira e feita uma análise cautelosa. Tratando-se, de acordo com o pesquisado, do primeiro estudo desta natureza em Portugal, ousamos refletir sobre os dados recolhidos.

Parece que se mantêm os mesmos problemas, talvez agravados por imposição de modelos de formação (tempos, componentes e estruturas) que aparentam ter efeitos cristalizadores em face de alguns problemas apontados para a formação de educadores/as e professores/as.

Quando se posicionam em relação à PES, os/as 115 estudantes-estagiários/as assumem esta experiência como um lugar importante no seu percurso formativo, manifestando consciência de que a profissão só se aprende na prática e numa relação dialógica com a reflexão sobre e na profissão.

Nesse campo da reflexão sobre e na profissão, a maioria afirmou fazer reflexões escritas durante o período da PES $(74,8 \%)$ e, daqueles/as que as realizam, $89,6 \%$ dos/as estudantes-estagiários/as reconhecem que estas têm impacto na sua ação pedagógica. Apenas 10,4\% afirmaram o contrário. Não obstante, é um valor que deve preocupar quem está implicado na formação desses/as profissionais, na medida em que se sabe que esse fator é um aliado de peso na formação da identidade profissional do/a educador/a e professor/a.

Um olhar adentro de outras variáveis permitiu encontrar algumas perplexidades e tensões, como a referência a modelos pedagógicos híbridos, inexistentes e/ou desconsiderados, e a eterna centralidade do par Psicologia e Pedagogia como as áreas científicas mais vezes referenciadas, ora pela valorização de autores clássicos da Psicologia, como Vygotsky e Piaget, ora pela maior expressão de autores/as nacionais. Este olhar analítico permite verificar a pouca atualizada bibliografia e diversificação de autores/as considerados/as neste percurso formativo. Não se pretende a desvalorização dos autores clássicos, nem das áreas científicas privilegiadas, estranha-se a ausência de opções bibliográficas que, pela sua própria 
natureza mais diversificada, traria uma reflexão mais rica, ampla e crítica do processo formativo de se construir a profissão.

Ainda assim, é possível concluir que os dados parecem apontar para o reconhecimento da importância da mobilização teórica no momento das reflexões escritas, realizadas em período de estágio.

No que diz respeito aos perfis exploratórios de práticas dos/as estudantes através de uma ACM, com projeção suplementar da variável curso, os resultados evidenciam três perfis distintos: dois deles diferenciados pelo impacto e a justificação das reflexões, pelo subsistema de ensino superior, natureza jurídica do subsistema e modelos pedagógicos; e um terceiro grupo diferenciado pelo modelo pedagógico adotado e o subsistema frequentado.

O primeiro perfil, marcado pela associação entre a adoção do modelo pedagógico em função do contexto e a proximidade da categoria relativa ao ensino universitário, é indício da volatilidade vivida nos dias de hoje. Parece indiferente que a profissão se construa assente em orientações pouco estruturadas.

O segundo perfil opõe-se ao primeiro, em particular na adoção clara de modelos pedagógicos - MEM e HighScope - e na frequência do ensino politécnico público. Sobressaem, ainda, o impacto que as reflexões escritas têm na PES e a assunção de que se configuram como um mecanismo de regulação/avaliação da ação ou como um processo de introspeção, necessários à consolidação da prática pedagógica desses/as estagiários/as. A Educacional Geral-Área da Docência e Educacional Geral são as componentes de formação privilegiadas.

O terceiro perfil é marcado pela ausência de impacto das reflexões na PES, destacando-se uma associação entre Didáticas Específicas, o modelo pedagógico do MEM e estudantes que não sabem ou não responderam à questão. Este perfil não deixa de revelar uma contradição evidente quando se confrontam a opção pelo modelo pedagógico do MEM e a desvalorização do impacto da reflexão escrita na PES, na medida em que este modelo pedagógico privilegia a abordagem reflexiva como elemento constitutivo e fundamental na formação do/a profissional de educação. É um perfil exploratório que não deixa de levantar questões relativamente à consistência da formação que é vivida. Será que o ritmo em que esta ocorre permite tomar consciência de todos os aspetos essenciais à apropriação do modelo pedagógico do MEM?

Em suma, o pluralismo interno que nos é dado pelos três perfis exploratórios parece tornar possível o registo de um período em que a própria PES, em particular, e a formação docente, em geral, se caracterizam pela sua constante instabilidade e incerteza. A refundação da formação de educadores/as e professores/as exige que se continue a investigar sobre a temática. Para que tenha alguma eficácia, a investigação terá que se ampliar, tanto no tamanho da amostra como na integração de outros atores educativos. 


\section{REFERÊNCIAS}

ALARCÃO, Isabel; ROLDÃO, Maria do Céu. Supervisão: um contexto de desenvolvimento profissional dos professores. Mangualde: Edições Pedagogo, 2010.

BIANCHETTI, Lucídio; SGUISSARDI, Valdemar (org.). Dilemas da pós-graduação: gestão e avaliação. Campinas: Autores Associados, 2009.

CARDONA, Maria João. Contributos para a história do grupo dos profissionais de Educação de Infância em Portugal. Interacções, Santarém, v. 4, n. 9, p. 4-31, 2008. Disponível em: https://revistas.rcaap.pt/interaccoes/ article/view/358. Acesso em: 5 ago. 2019.

CARVALHO, Helena. Análise multivariada de dados qualitativos: utilização de análise de correspondências múltiplas com SPSS. Lisboa: Sílabo, 2008.

COCHRAN-SMITH, Marylin; VILLEGAS, Ana Maria. Research on teacher preparation: charting the landscape of a sprawling field. In: GITOMER, D.; BELLS, C. (ed.). Handbook of research on teaching. Washington: AERA, 2016. p. 439-547.

DEMAZIÈRE, Didier. Typologie et description: à propos de l'intelligibilité des expériences vécues. Sociologie, v. 4, n. 3, p. 333-347, 2013.

ESTRELA, Maria Teresa; ESTEVES, Manuela; RODRIGUES, Ângela. Síntese da investigação sobre formação inicial de professores em Portugal (1990-2000). Porto: Porto, 2002. (Cadernos da Formação de Professores, 5).

EUROPEAN COMMISSION/EACEA/EURYDICE. The European Higher Education Area in 2018: Bologna Process Implementation Report. Luxembourg: Publications Office of the European Union, 2018.

FERREIRA, Pedro. Formação inicial de professores do $1^{\circ} \mathrm{CEB}$, supervisão pedagógica e inovação curricular: perceções e reflexões de supervisores e estagiários. 2016, 503 f. Tese (Doutorado em Ciências da Educação) - Universidade do Porto, Porto, 2016.

FERREIRA, Pedro; FERNANDES, Preciosa. Formação inicial de professores do $1^{\circ} \mathrm{CEB}$ : uma análise focada nos relatórios de estágio. Saber \& Educar, Porto, n. 20, p. 244-254, dez. 2015. Disponível em: http://revista.esepf. pt/index.php/sabereducar/article/view/157/pdf_21. Acesso em: 5 ago. 2019.

GALVÃO, Cecília; PONTE, João Pedro (org.). Práticas de formação inicial de professores: participantes e dinâmicas. Lisboa: Instituto de Educação, 2018.

LEITE, Carlinda. Percursos e tendências recentes da formação de professores em Portugal. Educação, Porto Alegre, v. 28, n. 3, p. 371-389, set./dez. 2005. Disponível em: http://www.redalyc.org/pdf/848/84805702.pdf. Acesso em: 5 ago. 2019.

LIMA, Licínio; AZEVEDO, Mário; CATANI, Afrânio. O Processo de Bolonha, a avaliação da educação superior e algumas considerações sobre a Universidade Nova. Avaliação: Revista da Avaliação da Educação Superior, Campinas, v. 13, n. 1, p. 7-36, mar. 2008. Disponível em: http://www.scielo.br/pdf/aval/v13n1/a02v13n1.pdf. Acesso em: 5 ago. 2019.

PORTUGAL. Ministério da Educação. Decreto-lei n. 43/2007, de 22 de fevereiro. Aprova o regime jurídico da habilitação profissional para a docência na educação pré-escolar e nos ensinos básico e secundário. Lisboa, 2007. Disponível em: https://dre.pt/pesquisa/-/search/517819/details/maximized. Acesso em: 28 jan. 2018.

PORTUGAL. Ministério da Educação. Decreto-lei n. 79/2014, de 22 de maio. Aprova o regime jurídico da habilitação profissional para a docência na educação pré-escolar e nos ensinos básico e secundário. Lisboa, 2014. Disponível em: https://dre.pt/pesquisa/-/search/25344769/details/maximized. Acesso em: 28 jan. 2018.

RAMALHO, Henrique. Sinuosidades da formação pedagógica e didática dos professores: entre a cultura da performatividade de feição técnico implementalista e o desafio da formação investigativo reflexiva. Saber $\mathcal{E}$ Educar, Porto, n. 20, p. 254-263, 2015. Disponível em: http://revista.esepf.pt/index.php/sabereducar/article/ view/172. Acesso em: 5 ago. 2019. 
SANTOS, Boaventura de Sousa. Para além do pensamento abissal: das linhas globais a uma ecologia de saberes. Novos Estudos Cebrap, São Paulo, n. 79, p. 71-94, nov. 2007. Disponível em: http://www.scielo.br/pdf/ nec/n79/04.pdf. Acesso em: 5 ago. 2019.

SERRALHEIRO, José. 0 processo de Bolonha e a formação dos educadores e professores portugueses. Porto: Profedições, 2005.

TOMÁS, Catarina; GONÇALVES, Carolina. A prática de ensino supervisionada nos mestrados de formação de educadores/as e professores/as em Portugal. Revista Práxis Educacional, Vitória da Conquista, v. 14, n. 30, p. 111-134, out. 2018. Disponível em: http://periodicos2.uesb.br/index.php/praxis/article/view/4363. Acesso em: 5 ago. 2019.

NOTA: Este artigo foi uma construção conjunta entre as autoras.

COMO CITAR ESTE ARTIGO

TOMÁS, Catarina; GONÇALVES, Carolina. Perfis de estagiários na prática de ensino supervisionada em Portugal. Cadernos de Pesquisa, São Paulo, v. 49, n. 174, p. 168-181, out./dez. 2019. https://doi.org/10.1590/198053146432 